\title{
Shaping RNA Structures with Metal lons and Metal Ion Complexes
}

\author{
Roland K. O. Sigel $\S^{\star}$ and Sofia Gallo
}

§Werner Prize Winner 2009

\begin{abstract}
The research in our laboratory focuses on the role of metal ions and their complexes in structure formation and folding of nucleic acids. Large catalytic RNAs, like group II introns and some riboswitches, as well as shorter RNAs and DNAs containing modified nucleotides for the assembly of nanodevices are examined. Abundant metal ions like $\mathrm{Mg}^{2+}$ or natural metabolites like coenzyme $\mathrm{B}_{12}$ are in the center of interest, but also other metal ions, complexes thereof and $\mathrm{B}_{12}$ derivatives are applied with the aim to understand the largely unknown and manifold non-covalent interactions with nucleic acids. We apply a multitude of techniques, including potentiometric $\mathrm{pH}$ titrations, NMR spectroscopy, X-ray crystallography, gel electrophoresis and single molecule FRET experiments. Here we briefly summarize each of our research topics emphasizing the interaction of coenzyme $\mathrm{B}_{12}$ and its derivatives with the btuB riboswitch of $E$. coli. This highly conserved sequence, found in the 5'-untranslated region (5'-UTR) of the btuB mRNA, is involved in the regulation of the btuB protein expression. After a summary on the historical discovery of such riboswitches and their mechanism of action, we shortly focus on our own contributions to understand the structural equilibrium, high affinity and selectivity of the interaction between this specific RNA sequence and the largest and most complex cellular metabolite, coenzyme $B_{12}$.
\end{abstract}

Keywords: Coenzyme $B_{12}$. Metal ions · Ribozymes · Riboswitches · RNA/DNA

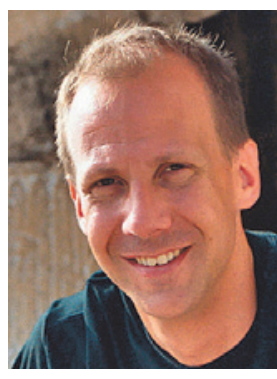

Roland K. O. Sigel is Associate Professor (2009) of Inorganic Chemistry at the University of Zurich. He studied chemistry at the University of Basel, received his $\mathrm{PhD}$ summa cum laude (1999) from the University of Dortmund, and thereafter spent nearly three years at Columbia University, New York. He has received several fellowships, was endowed with a SNF-Förderungsprofessur (2003-2008), invited to plenary lectures at several international conferences, and in 2009 he received a Lectureship of the Hungarian Chemical Society. In 2008 he has been awarded the EuroBIC Medal and in 2009 the Werner Prize of the Swiss Chemical Society. His research focuses on

${ }^{*}$ Correspondence: Prof. Dr. R. K. O. Sigel University of Zurich

Institute of Inorganic Chemistry

Winterthurerstrasse 190

$\mathrm{CH}-8057$ Zürich

Tel.: +41446354652

Fax.: +414463568 02

E-mail: roland.sigel@aci.uzh.ch the characterization of metal ion-nucleic acid interactions, and he is a co-editor of the series Metal Ions in Life Sciences.

\section{Introduction}

Since the discovery of catalytically active RNA sequences, named ribozymes from here on, by the Cech and Altman laboratories in the early $1980 \mathrm{~s},{ }^{[1,2]}$ the knowledge on functional RNAs, being either synthetic or natural, has steadily increased. Today it is known that RNA is involved in a multitude of cellular processes, sometimes also performing catalytic functions. RNA molecules can thereby act either independently of any protein cofactor or as RNAprotein complexes, e.g. the ribosome (protein biosynthesis) or the spliceosome (mRNA splicing in eukaryotic cells). ${ }^{[3]}$

Independent of the nucleic acids' size and function, metal ions are the most crucial and abundant cofactors, determining folding, global, and local structures, as well as taking directly part in catalysis of ribozymes. ${ }^{[4]} \mathrm{Mg}^{2+}$ and $\mathrm{K}^{+}$are usually considered the naturally involved metal ions with nucleic acids in the cell. ${ }^{[5]}$ However, also other metal ions are available and might take part in folding and catalysis..$^{[5-8]}$ In all cases it is unknown so-far how metal ions exactly influence the structure and activity on the atomic level. To answer this fundamental question is the driving force of our research.

\section{Metal ions in the Catalytic Center of Group II Intron Ribozymes}

Group II introns are natural self-splicing catalytic RNAs and are among the largest ribozymes known. ${ }^{[9]}$ They occur in some bacteria, but mainly in plants, fungi, and lower eukaryotes. These macromolecules are closely related to the eukaryotic splicing machinery and are considered the ancestors of up to about $40 \%$ of the human genome. ${ }^{[10]}$ Group II introns catalyze a diverse set of reactions like splicing but also reinsertion into DNA, being mobile genetic elements. The nature of the metal ion present in solution has thereby a strong influence on the catalytic activity of these ribozymes. ${ }^{[8,11-13]}$ Recently, a first X-ray structure of a self-splicing group II intron has been solved, although unfortunately at too low resolution to learn much about the metal ions present. ${ }^{[14]}$

We aim to determine the specific metal ion binding sites within the active structure and characterize their thermodynamic properties. By means of NMR, we determine the solution structures of domains and subdomains which are part of the catalytic core and subsequently characterize their metal ion binding properties by various spectroscopic techniques (Fig. 1). ${ }^{[15-22]}$ One of the biggest challenges is the determination of the metal ion affinities because usually several metal ions simultaneously bind to one RNA molecule with similar affinities. We have thus developed 
an iterative approach to calculate the intrinsic binding constants of different metal ions to one ligand, e.g. a RNA hairpin, based on NMR titration experiments. ${ }^{[17]}$ Further NMR experiments are conducted to identify the specific liganding atoms of the RNA:[18] The main problem hereby lies in the fact that each of the four nucleotide building blocks offers a multitude of potential coordination sites, e.g. the phosphate oxygens or the N(7) of the purines. At the same time inner-sphere, i.e. direct coordination, or outer-sphere binding, mediated through a water molecule, can take place, further complicating the situation. Nevertheless, a surprising selectivity and specificity of RNAs for given metal ions is reached, ${ }^{[8]}$ which we aim to reveal on the coordination chemical level (for a recent review, see ref. [21]). Only in this way will we finally be able to understand the ribozyme mechanism and modify these molecules for further needs.

\section{From $\mathbf{M}^{\mathrm{n}+}$ Binding to Nucleotides to Nucleic Acids}

Metal ion coordination to mononucleotides is relatively well understood.[24-26] In the past years, we have extended these studies towards phosphorothioate derivatives, ${ }^{[27,28]}$ dinucleotides, ${ }^{[29-31]}$ as well as the binding of two metal ions to one nucleobase. ${ }^{\left[{ }^{2}\right]}$ Surprisingly, in the latter case, the binding of the second metal ion is only slightly hampered by the presence of the first one. ${ }^{[32]}$ We have now used this accumulated wealth of information to create a library of stability increments for the individual liganding atoms towards $\mathrm{Mg}^{2+}, \mathrm{Ca}^{2+}$, $\mathrm{Mn}^{2+}, \mathrm{Cu}^{2+}, \mathrm{Zn}^{2+}, \mathrm{Cd}^{2+}$ or $\mathrm{Pb}^{2+}{ }^{233]}$ These increments can be applied to estimate the intrinsic affinities of nucleic acid-binding pockets for the mentioned metal ions and thus to provide first insights into the thermodynamics of individual binding pockets within large nucleic acid structures.

To assist the above-mentioned approach of adding up stability increments and to allow for a rigorous examination of all known metal ion binding pockets, we have built up a freely available database on Metal Ions in Nucleic AcidS (MINAS) (Fig. 2). ${ }^{[34]}$ This database can be used to evaluate, visualize, and characterize the metal ion binding sites of all structures deposited in the PDB and NDB.

\section{Metal Ion-assisted Folding of Large RNAs}

Metal ions induce and direct the folding of RNAs. ${ }^{[35,36]}$ In most cases, the presence of divalent metal ions leads to a rapid collapse into different kinetic traps and to

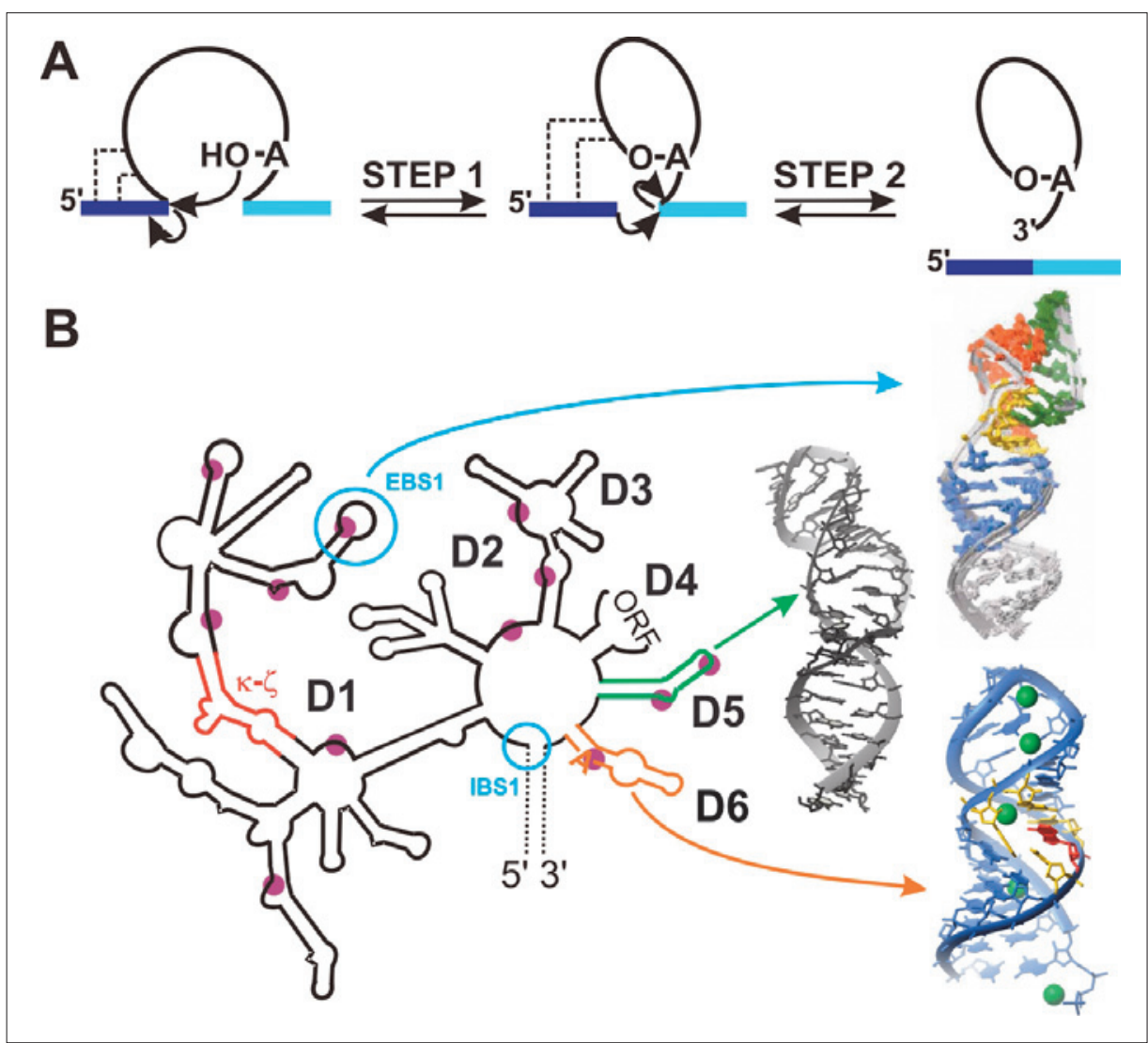

Fig. 1. Group II intron ribozymes. (A) Schematic splicing reaction, i.e. the removal of the intronic sequence and joining of the two flanking exons. Both steps are reversible and performed without the aid of proteins. (B) Schematic secondary structure of the yeast mitochondrial group II intron Sc.ai5 $\gamma$. Regions that are part of the catalytic core and in the focus of our research are colored and metal ion binding sites indicated as magenta spheres. NMR solution structures of the intronexon interaction, domains 5 and 6 , as solved in our lab, are shown to the right, based on the PDB files $2 \mathrm{~K} 64,{ }^{[20]} 1 \mathrm{R} 2 \mathrm{P},{ }^{[15]}$ and $2 \mathrm{AHT}{ }^{[16]}$ and prepared with MOLMOL. ${ }^{[23]}$ Domain 5 is the most conserved region of the intron and domain 6 contains the nucleophile in the first step of splicing.

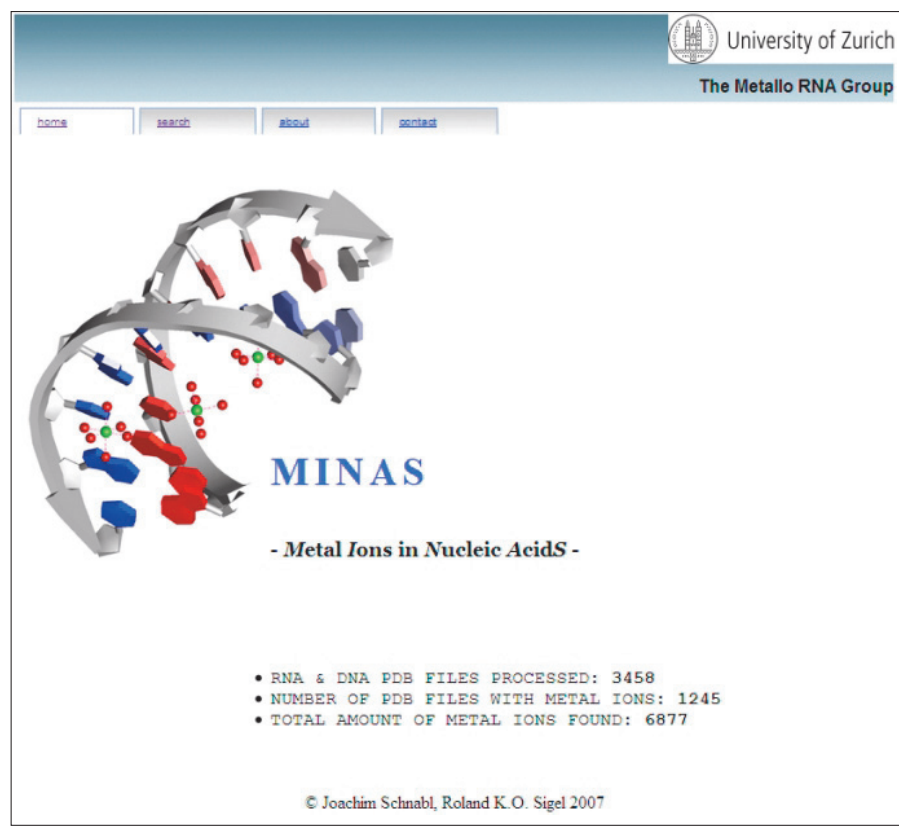

Fig. 2. Database of Metal Ions in Nucleic AcidS (MINAS; www. minas.uzh.ch). This database contains all metal ion-nucleic acid structures of the PDB and NDB and allows a detailed analysis of the metal ion coordination spheres.

a subsequent slow three-dimensional rearrangement of the (sub)domains into the active structure. ${ }^{[37,38]}$ Group II introns behave differently: A first slow folding step is followed by a series of fast consecutive steps obeying a straight pathway devoid of kinetic traps.[39-41] We have recently characterized the folding pathway of one of these large RNAs by single molecule Fluorescence Resonance Energy Transfer 


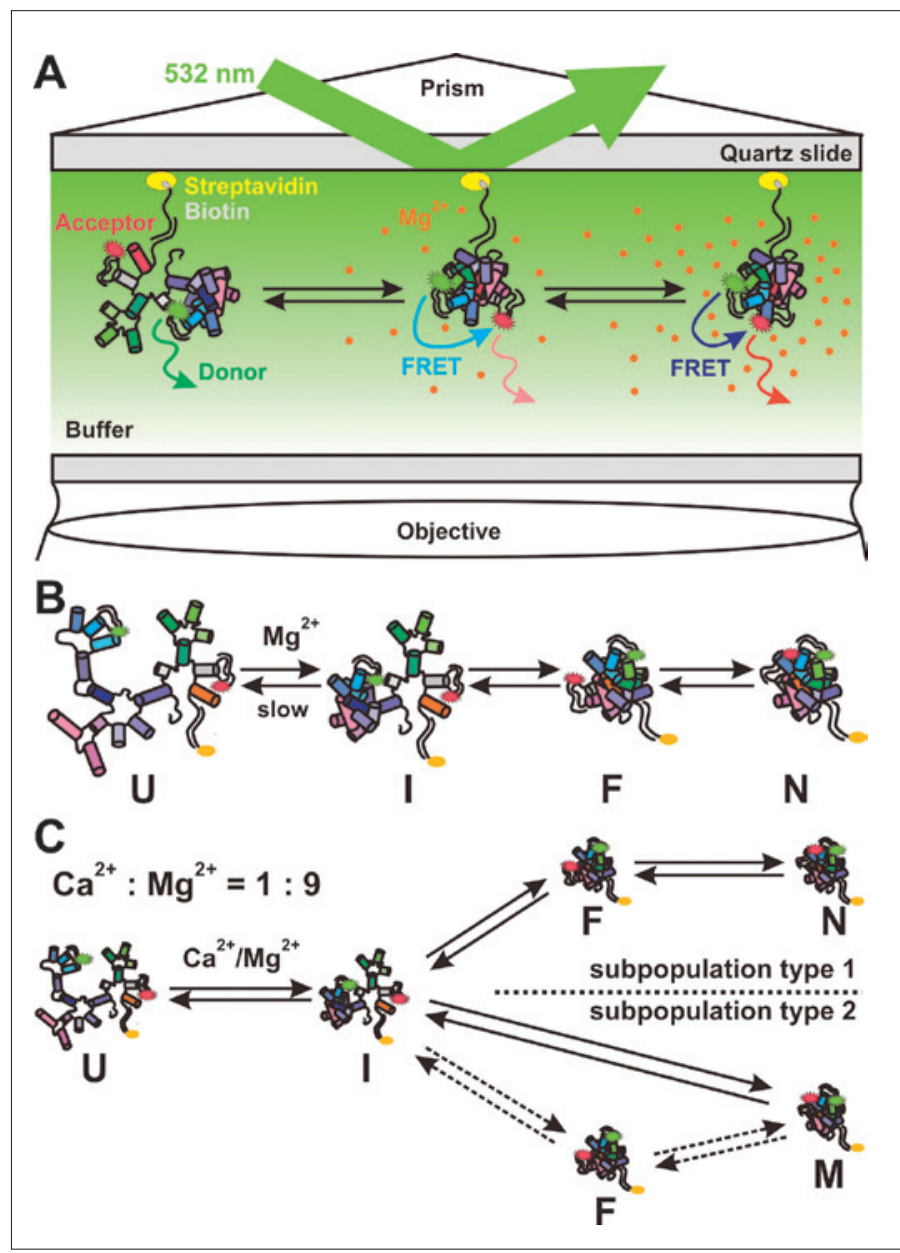

Fig. 3. Single molecule FRET studies of group II intron folding. (A) Schematic setup of smFRET experiments: The RNA molecules are attached via a biotin/ streptavidin interaction to a quartz slide, the donor fluorophore excited by a laser, and the fluorescence measured by a CCD camera from below. (B) Folding pathway of a Sc.ai5 $\gamma$ derived ribozyme construct in the presence of $\mathrm{Mg}^{2+}$ only being devoid of kinetic traps $(\mathrm{U}$, unfolded; I, intermediate, $\mathrm{F}$, folded; $\mathrm{N}$, native state). (C) Folding pathway in the presence of $\mathrm{Ca}^{2+}$. The molecules fold into two distinct subpopulations that do not interchange (U, unfolded; I, intermediate, $\mathrm{F}$, folded; $\mathrm{M}$, misfolded; $\mathrm{N}$, native state).

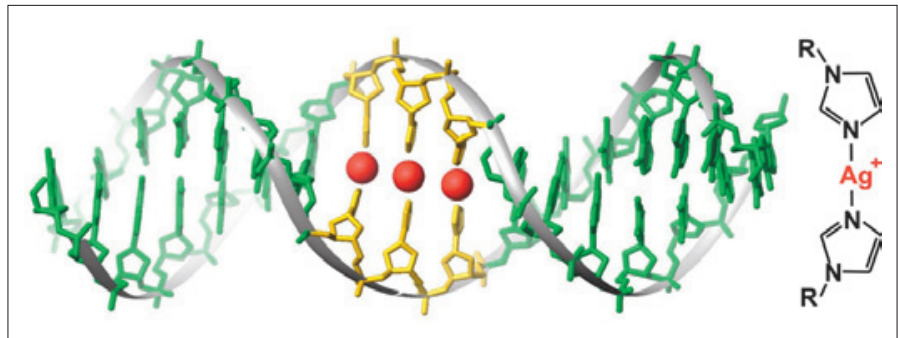

Fig. 4. First NMR solution structure of a metal-modified DNA duplex containing three imidazole- $\mathrm{Ag}^{+}$-imidazole base pairs in its center, as indicated on the right. The $\mathrm{Ag}^{+}$ions are shown by red spheres. The Fig. has been prepared based on the structure $2 \mathrm{KE}^{[46]}$ using MOLMOL. ${ }^{[23]}$

(smFRET) spectroscopy ${ }^{[42]}$ and investigated the effect of $\mathrm{Ca}^{2+}$ on this folding pathway (Fig. 3):[43] Already small amounts of $\mathrm{Ca}^{2+}$ affect the global structure of this $\sim 700$ nucleotide long RNA. Unprecedentedly, two distinct subpopulations were observed that do not interchange with each other. It was highly surprising to see the single molecules fold into two distinctly different three-dimensional structures occurring in parallel under the same conditions. ${ }^{[43]}$

\section{From Nature to Nano-devices}

Metal ions usually bind to the major and minor groove edges of nucleotides within duplex or complex nucleic acids as they occur manifold in nature. Our interests lie in the investigation of structures containing metal ions in the center of the nucleic acid duplex. For example, $\mathrm{Hg}^{2+}$ ions can be 'trapped' in the helix center between two opposite thymine or uracil nucleobases, which become deprotonated upon coordinating the metal ion at N(3). ${ }^{[44,45]}$ Recently we succeeded in determining the first three-dimensional structure of a metallated DNA duplex containing artificial imidazole nucleotides with three linearly coordinated $\mathrm{Ag}^{+}$ions aligned in the middle (Fig. 4). ${ }^{[46]}$ Based on solution structures and investigations on the metal ioninitiated structural changes as performed in our laboratory, the aim is to construct nanodevices with particular electric, magnetic and sensing properties. ${ }^{[47,48]}$

\section{Sensing Metal Ion Metabolites by RNA}

Riboswitches are recently discovered highly conserved sequences in the untranslated regions (UTR) of mostly bacterial mRNAs. Upon binding to certain metabolites with high specificity and selectivity these RNAs change their three-dimensional structure thus regulating gene expression and metabolite concentration on the translational or transcriptional level. ${ }^{[49]}$ Our research focuses on the $\mathrm{Mg}^{2+}$ - and coenzyme $\mathrm{B}_{12}$-sensitive riboswitches ${ }^{[50,51]}$ whereby the latter is explained in more detail in the following Section.

\section{Riboswitches}

Riboswitches are conserved sequences within mRNA guiding very elegantly protein-independent gene-regulation. ${ }^{[49,51-54]}$ Out of the more than 20 riboswitch classes discovered so far, only the TPP-binding riboswitch is known to be present also in archeae, fungi and plants, ${ }^{[55-58]}$ whereas all others are restricted to bacteria where they are believed to regulate up to $2 \%$ of the genes. ${ }^{[59]}$ Due to their overwhelming occurrence in bacteria, riboswitches are of increasing interest as new targets for the design of antimicrobial drugs. ${ }^{[60]}$

Riboswitches act as natural aptamers that bind to small metabolites with very high affinity. Such metabolites are amino acids, purine bases, redox cofactors, metal ions, second messengers and others. It is highly intriguing how RNA composed of only four building blocks is able to recognize and bind such a variety of ligands different in size, charge and functional groups. As it turns out, hydrogenbonding, electrostatic and van der Waals interactions as well as Watson-Crick base pairing and stacking interactions are used concomitantly to ensure specificity and affinity. ${ }^{[56,61-63]}$

Riboswitches generally consist of a highly conserved aptamer domain, a region of 35 to 260 nucleotides, which represents the metabolite binding part, and a downstream expression platform. Metabolite binding causes considerable conformational changes in secondary and tertiary structure and subsequent reorganization of the expression platform, the latter being finally responsible for gene regulation. The downstream genes all have a close physiological relationship with the bound metabolite, i.e. they encode for transport proteins or proteins involved in the biosyn- 


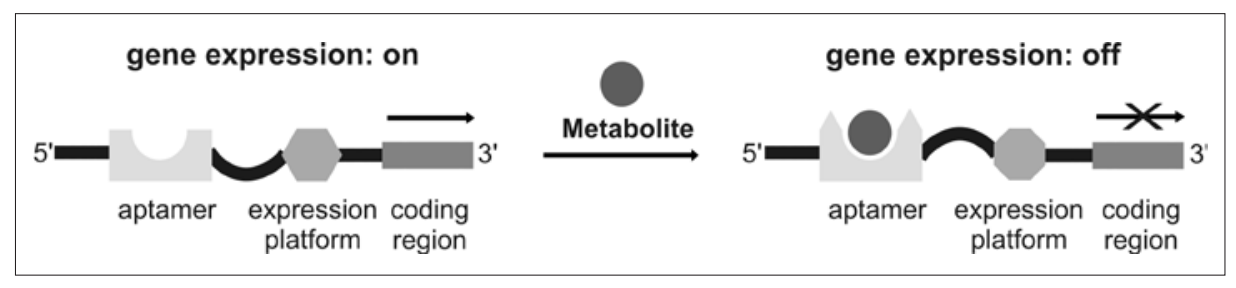

Fig. 5. General mechanism of a riboswitch. Binding of the metabolite to its aptamer region of the riboswitch leads to a structural rearrangement of this domain as well as of the expression platform and subsequently to an altered gene expression. Such metabolites are amino acids (lysine and glycine), purine bases (adenine, guanine and prequenosine-1), cofactors (AdoCbl, flavin mononucleotide, S-adenosyl methionine, tetrahydrofolate, thiamine pyrophosphate, molybdenum and tungsten cofactors), metal ions $\left(\mathrm{Mg}^{2+}\right)$, small nucleotide-units acting as second messenger (c-di-GMP) or others (glucosamine-6-phosphate, S-adenosyl homocysteine) ${ }^{[49]}$

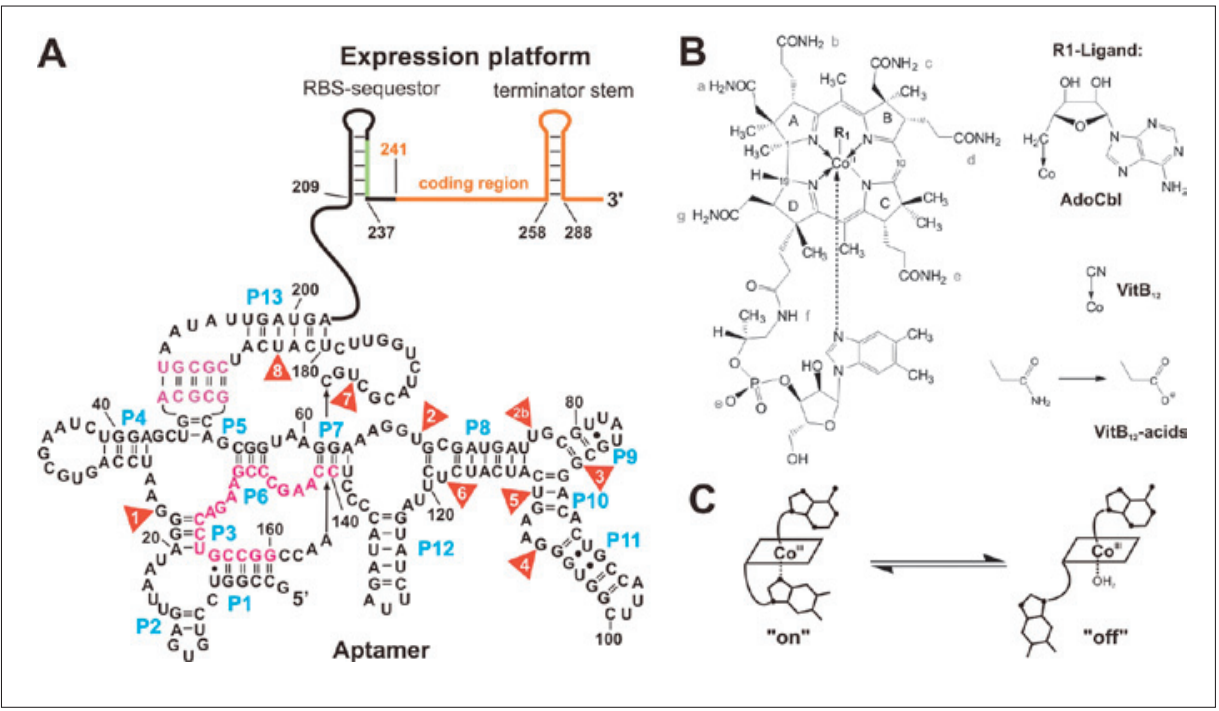

Fig. 6. The btuB riboswitch and its metabolite coenzyme $B_{12}$. (A) Secondary structure of the $b t u B$ riboswitch from $E$. coli in the presence of AdoCbl. The aptamer region of the riboswitch covers nucleotide 1 to 202 and includes a pseudoknot (magenta) and the $B_{12}$-box (pink). ${ }^{[7]}$ The expression platform is situated between nucleotides 209 and 288 and contains a translational regulatory element (the ribosomal binding site(RBS)-sequestor hairpin with the Shine-Dalgarno sequence in light green) ${ }^{[72]}$ and a transcriptional regulatory element (termination stem) being part of the coding sequence (orange). ${ }^{[33]}$ (B) General formula of $B_{12}$ molecules with an axial dimethyl benzimidazole ligand as present in AdoCbl, $\mathrm{VitB}_{12}$, and their acid derivatives. (C) Intramolecular equilibrium between the 'base-on' and 'base-off' forms of the $B_{12}$ derivatives. Under physiological conditions, AdoCbl is found exclusively in the 'base-on' form, whereas in the case of adenosyl factor A the 'base-off' form prevails.

thesis of the metabolite (Fig. 5). Regulation can thereby occur based on structural changes, self-cleavage ${ }^{[64]}$ or (alternative) splicing. [49,57] Genetic control is mostly negative (i.e. switching off gene expression) but there are also some examples of a positive feedback such as the adenine responding $y d h L$ riboswitch. ${ }^{[65]}$ In addition, cooperativity[66] or multiple recognition units within so-called tandem riboswitches are known. [67,68]

\subsection{Discovery and Structures of $B_{12}$ Responsive RNAs}

$\mathrm{B}_{12}$ sensing riboswitches are widespread throughout the bacterial kingdom and are found in nearly all taxonomic groups. They control gene products involved in cobalamin synthesis and trans- port, cobalt transport, $\mathrm{B}_{12}$-independent aerobic and anaerobic ribonucleotide reductase synthesis, as well as glutamate and succinate fermentation. ${ }^{[69]}$

Kadner and coworkers recorded the first structural influence of vitamin $B_{12}$ $\left(\mathrm{VitB}_{12}\right)$ and adenosyl cobalamin (coenzyme $\mathrm{B}_{12}$, AdoCbl) on a naturally occurring RNA in 1991 with the btuB leading sequence of E. coli (Fig. 6A). ${ }^{70]}$ Subsequent investigations with the $b t u B$ gene and $c o b$ operon of $S$. typhimurium revealed a highly conserved 25-nt long sequence essential for gene regulation and highlevel expression called the $\mathrm{B}_{12}$-box. ${ }^{[73,74]}$ By reverse transcription three highly structured regions were identified within this RNA:[72] i) the ribosome binding site at Thy256, ii) Ade 202 marking the start of the $b t u B$ aptamer region, and iii) Cyt161 at the beginning of the $B_{12}$ box. Whereas the latter structure is independent of AdoCbl, the Ade202 region showed a clear structural dependence on AdoCbl concentration. In 2003, a sequence alignment of approximately $200 \mathrm{~B}_{12}$-aptamers revealed a high degree of sequence conservation and a first common secondary structure could be proposed. ${ }^{[75]}$ This consensus sequence included six hairpins arranged around a central wheel as well as an antiterminator or/and an antisequestor hairpin belonging to the expression platform.

Further investigations revealed two types of $\mathrm{B}_{12}$ aptamers: The first includes the $b t u B$ riboswitches and the longer $c o b$ operon leading sequence with at least ten base-paired regions and around 57 conserved nucleotides. The second class was found in B. subtilis, upstream of the $y v r C$ gene lacking the large part around helices P8 to P12.[71]

\subsection{Gene Regulation by the $B_{12}$ Sensing Riboswitches}

Depending whether an organism can synthesize or has to take up coenzyme $\mathrm{B}_{12}$, $\mathrm{B}_{12}$-dependent riboswitches control genes involved in the biosynthesis of $\mathrm{B}_{12}$ (e.g. S. typhimurium) or uptake and transport of the same (e.g. E. coli). For example, the cob operon of $S$. typhimurium encodes 20 proteins of the cobalamin biosynthetic pathway and is controlled by the cob riboswitch. ${ }^{[76,77]}$ Instead, the btuB riboswitch regulates a single gene encoding for an outer membrane transporter responsible for the active transport of cobalamins into the periplasmic space. ${ }^{[78-80]}$ Both riboswitches are negatively controlled on both the transcriptional and the translational level and the structural rearrangements seem to correlate well. ${ }^{[70,81]}$ In the $b t u B$ riboswitch, the first 240 nucleotides are responsible for the translational control of gene expression by sequestration of the Shine-Dalgarno sequence, the binding site of the 16S rRNA unit of the ribosome (Fig. 6A). Instead, the first 100 nucleotides of the coding sequence are compulsory for a Rho-independent transcriptional regulation (Fig. 6). ${ }^{[73]} \mathrm{A}$ possible mechanism of gene regulation is the formation of a pseudo-knot upon binding to AdoCbl and the resulting reorganization of the expression platform. However in-line probing experiments demonstrated also a substantial structural rearrangement of the aptamer region upon binding to $\mathrm{AdoCbl}$ and some of its derivatives (Fig. 7). [53]

\subsection{Specific Recognition of AdoCbl by the btuB Riboswitch}

The organometallic complex coenzyme $B_{12}$ is the largest and most complex of all coenzymes (Fig. 6B). AdoCbl and its 


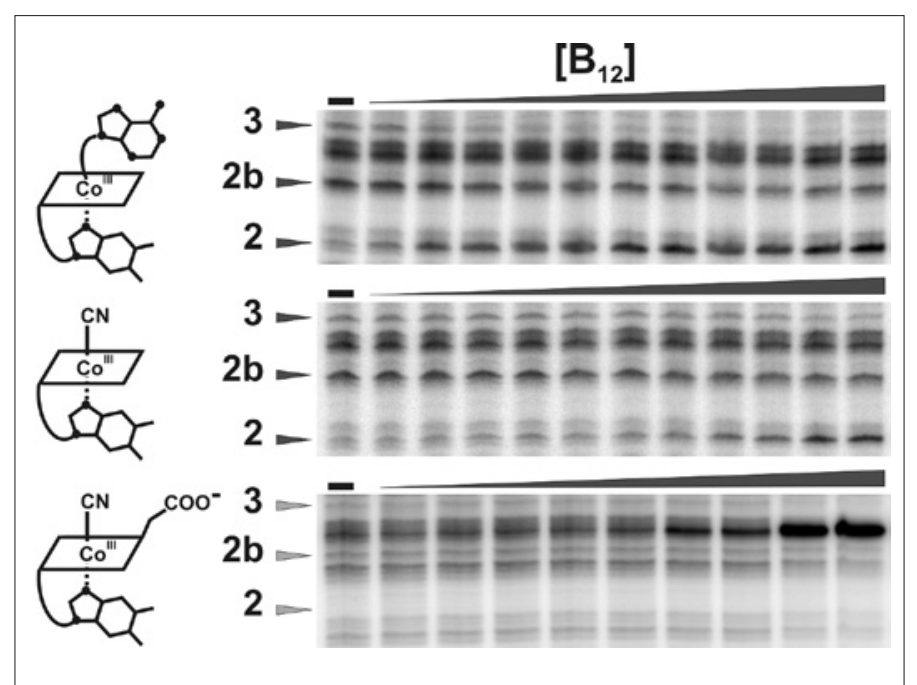

Fig. 7. In-line probing experiments with the btuB riboswitch in the presence of different $B_{12}$ derivatives. Addition of AdoCbl (top) leads to the decrease of the intensity of bands 3 and $2 \mathrm{~b}$ while cleavage

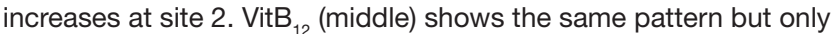
at higher concentrations. $c$-acid VitB $_{12}$ (bottom) binds, but prevents the riboswitch from a correct rearrangement, as is obvious from the different cleavage pattern of the RNA. $B_{12}$ concentrations range from $30 \mathrm{nM}$ to $0.1 \mathrm{mM}$ (AdoCbl), $3.3 \mu \mathrm{M}$ to $10 \mathrm{mM}\left(\mathrm{VitB}_{12}\right)$, and $1 \mu \mathrm{M}$ to 0.75 $\mathrm{mM}\left(c\right.$-acid VitB $\left.{ }_{12}\right)$.

derivatives are considered the evolutionary most ancient protein cofactors $^{[82-84]}$ and might have already played a role in the so-called RNA world. ${ }^{[85]}$ This ancient relationship between a nucleic acid and this fascinating metal ion complex triggered our interest already some time ago.

The first example of a RNA that binds specifically to a $\mathrm{B}_{12}$ derivative was discovered in 1994 by Szostak and coworkers in in vitro selection experiments. ${ }^{[86]}$ This synthetic aptamer of 35 nucleotides in length selectively binds $\operatorname{VitB}_{12}\left(K_{\mathrm{D}}=90 \mathrm{nM}\right)$ over other $\mathrm{B}_{12}$ derivatives such as dicyanocobinamide $(20 \mathrm{mM})$ or the larger AdoCbl, which does not bind. The X-ray crystal structure[87] revealed that a large hydrophobic pocket is situated at the interface between a small duplex and a unique triple helix structure. Selective VitB $_{12}$ binding is achieved by a dense network of different interactions including hydrophobic and electrostatic interactions, hydrogen-bonding as well as the insertion of the cyanide ligand of $\mathrm{VitB}_{12}$ into the base-triplet of the triple helix, the latter explaining the selectivity for cyanide-carrying $B_{12}$ molecules.

As numerous $\mathrm{B}_{12}$ derivatives occur in nature, a different selection scheme is expected for natural $B_{12}$ aptamers. Indeed, the two best studied $\mathrm{B}_{12}$ riboswitches, the $b t u B$ riboswitch and the leading sequence of the $c o b$ operon, show a high selectivity for AdoCbl (the most abundant form of $\mathrm{B}_{12}, K_{\mathrm{D}}=89 \pm 6 \mathrm{nM}$ with btuB) over $\operatorname{VitB}_{12}{ }^{12}\left(K_{\mathrm{D}}=314 \pm 141 \mu \mathrm{M}\right) \cdot{ }^{[50,53,81]}$ Our investigations concentrate currently on the structural basis for the interaction between AdoCbl and the 202 nt long aptamer region of the $b t u B$ riboswitch of $E$. coli. ${ }^{[51]}$ In contrast to $\mathrm{VitB}_{12}$, AdoCbl is able to release the lower dimethylbenzimidazol ligand in an intramolecular equilibrium, i.e. leading to a 'base-off' form (Fig. 6C). From protein interactions it is known that either the 'base-on' or the 'base-off' form can be bound.

In order to elucidate the binding mode to the riboswitch, we applied various structurally different $\mathrm{B}_{12}$ derivatives, i.e. missing either the upper $\left(\mathrm{VitB}_{12}\right)$, the lower (adenosyl cobinamide) or both large apical ligands (dicyanocobinamide), or displaying the 'base-off'-form (adenosyl factor A). [51] The conformational changes of the RNA upon interaction with the different $B_{12}$ derivatives was visualized by in-line probing experiments, i.e. structure-dependent selfdegradation of RNA (Fig. 7). The conformational switch of the RNA was followed by the appearance or disappearance of nine distinct cleavage bands upon binding to AdoCbl (Fig. 7). ${ }^{[51,53]}$ The nine cleavage sites are spread over the whole sequence, implying that binding to AdoCbl leads to an overall structural rearrangement of the RNA.

In contrast to earlier studies, ${ }^{[53,71,72]}$ our experiments showed the adenosyl-moiety on the upper side of the corrin ring not to be compulsory for the switching of the RNA. ${ }^{[51]}$ If present in high concentrations, also VitB induces a correct switch of the btuB RNA (Fig. 7). Similarly, the pres- ence and conformation of the lower part of the $\mathrm{B}_{12}$ derivative is of minor importance. Adenosyl cobinamide as well as the sterically more demanding adenosyl factor A (AdoFactA) allow essentially the same rearrangement of the riboswitch as AdoCbl. The unexpected high affinity for AdoFactA $\left(K_{\mathrm{D}}=290 \pm 32 \mathrm{nM}\right)$ further suggests that the 'base-off' nature of this ligand does not disturb the interaction with the RNA. UV studies showed further that the lower base is not replaced by a RNA nucleotide at the cobalt coordination site. ${ }^{[51]}$ As a direct consequence of the indicated results, one can conclude that the presence of the two axial ligands increase the $\mathrm{B}_{12}$-RNA interaction each by a factor of almost 1000. ${ }^{[51]}$

In contrast, the corrin ring with its side chains is directly responsible for the structural switch of the btuB RNA. We investigated the role of single amide side chains on riboswitch restructuration by applying $\mathrm{B}_{12}$ derivatives such as the $b-, c-, d$ - and $e$-acid derivatives of $\mathrm{VitB}_{12}$ (Fig. 6B) in in-line probing experiments. Application of these derivatives, all having one single amide group replaced by a carboxylic acid, provides a first insight in the importance of the correct $\mathrm{H}$-bonding pattern and electrostatic environment on btuB RNA switching. ${ }^{[50]}$ Interestingly, most $\mathrm{B}_{12}$-acid derivatives only lead to a partial rearrangement, whereas binding of the $c$-acid $\mathrm{B}_{12}$ is followed by a completely altered structural change. These findings corroborate the hypothesis that the amide side chains of the corrin ring are of uttermost importance for btuB RNA switching.

\section{Conclusions and Outlook}

The specific coordination of metal ions and metal ion complexes to nucleic acids is highly complex and goes in most instances far beyond a simple coulombic interaction. Relatively fast ligand exchange rates, rather low affinities, and the mostly spectroscopically silent metal ions involved, make the characterization of this interplay highly challenging. ${ }^{[5,8]}$ The combination of inner-sphere metal ion coordination with an extensive hydrogen bonding network via coordinated water molecules allows on the one hand a rather tight binding in preformed pockets, but on the other hand also a high degree of flexibility and dynamics. The dynamics of metal ion binding seem to play a crucial role for ribozyme activity, e.g. single group II intron molecules become more dynamic in their domain movements with increasing $\mathrm{Mg}^{2+}$ concentration. ${ }^{[42]}$

Our efforts aim to elucidate the basic principles of metal ion binding and to characterize the effect thereof on global structure, dynamics, and catalytic mechanism. 
The importance of the knowledge of, e.g. the intrinsic binding affinities is exemplified by the recent discovery that the catalytic rate of the hammerhead ribozyme is directly dependent on the phosphate affinity of the divalent metal ion present. ${ }^{[8]}$ Such relatively 'simple' correlations might turn out to be also true for other small ribozymes. In the case of the large ribozymes, more complicated interdependencies between metal ions and the RNA are to be expected because of the above-mentioned reasons.

To conclude, a highly interdisciplinary approach will be needed to understand the diverse world of ribozymes and riboswitch structures and functions depending on metal ions and/or metal ion complexes. At the same time we may expect surprising and unprecedented turns and twists in this fascinating field of Biological Inorganic Chemistry.

\section{Acknowledgement}

Roland Sigel thanks all his past and present group members for their hard work, enthusiasm, and great atmosphere in the lab, as well as many colleagues and friends from across the world for very fruitful collaborations. Special thanks go to Professor Dr. Heinz Berke who invited him to start his career at the University of Zurich in early 2003 as an Oberassistent in his group at the Institute of Inorganic Chemistry. Continuous financial support by the Swiss National Science Foundation (SNF-Förderungsprofessur, ERAnet Chemistry as well as direct project fundings), the Institute of Inorganic Chemistry, the University of Zürich, the Roche Research Foundation, the Novartis Stiftung, the NCCR Structural Biology, and the Swiss State Secretariat for Education and Research (COST D39 programme) is gratefully acknowledged.

Received: February 16, 2010

[1] K. Kruger, P. J. Grabowski, A. J. Zaug, J. Sands, D. E. Gottschling, T. R. Cech, Cell 1982, 31, 147 .

[2] C. Guerrier-Takada, K. Gardiner, T. Marsh, N Pace, S. Altman, Cell 1983, 35, 849 .

[3] R. F. Gesteland, T. R. Cech, J. F. Atkins, 'The RNA World', 3rd ed., Cold Spring Harbor Press, 2006.

[4] J. K. Frederiksen, R. Fong, J. A. Piccirilli, in 'Nucleic Acid-Metal Ion Interactions', Ed. N. V. Hud, Royal Society of Chemistry, Cambridge, UK, 2009, pp 260-306.

[5] E. Freisinger, R. K. O. Sigel, Coord. Chem. Rev 2007, 251, 1834

[6] M. Roychowdhury-Saha, D. H. Burke, RNA 2006, 12, 1846.

[7] J. L. Boots, M. D. Canny, E. Azimi, A. Pardi, RNA 2008, 14, 2212.

[8] J. Schnabl, R. K. O. Sigel, Curr. Op. Chem. Biol. 2010, available online, doi:10.1016/j. cbpa.2009.11.024.

[9] K. Lehmann, U. Schmidt, Critical Rev. Biochem Mol. Biol. 2003, 38, 249.

[10] J. D. Boeke, Genome Res. 2003, 13, 1975.

[11] R. K. O. Sigel, A. M. Pyle, Chem. Rev. 2007, 107, 97.

[12] R. K. O. Sigel, Eur. J. Inorg. Chem. 2005, 12, 2281.

[13] M. C. Erat, R. K. O. Sigel, J. Biol. Inorg. Chem. 2008, 13, 1025.
[14] N. Toor, K. S. Keating, S. D. Taylor, A. M. Pyle, Science 2008, 320, 77.

[15] R. K. O. Sigel, D. G. Sashital, D. L. Abramovitz, A. G. Palmer III, S. E. Butcher, A. M. Pyle, Nat. Struct. Mol. Biol. 2004, 11, 187.

[16] M. C. Erat, O. Zerbe, T. Fox, R. K. O. Sigel, ChemBioChem 2007, 8, 306.

[17] M. C. Erat, R. K. O. Sigel, Inorg. Chem. 2007, $46,11224$.

[18] M. C. Erat, H. Kovacs, R. K. O. Sigel, J. Inorg. Biochem. 2010, available online, doi: 10.1016/j. jinorgbio.2010.01.008.

[19] D. Kruschel, R. K. O. Sigel, J. Inorg. Biochem. 2008, 102, 2147.

[20] D. Kruschel, R. K. O. Sigel, submitted for publication.

[21] S. Johannsen, M. M. T. Korth, J. Schnabl, R. K. O. Sigel, Chimia 2009, 63, 146.

[22] M. Furler, B. Knobloch, R. K. O. Sigel, Inorg. Chim. Acta 2009, 362, 771.

[23] R. Koradi, M. Billeter, K. Wüthrich, J. Mol. Graphics 1996, 14, 29; R. Koradi, M. Billeter, K. Wüthrich, J. Mol. Graphics 1996, 14, 51.

[24] H. Sigel, Pure Appl. Chem. 2004, 76, 375.

[25] H. Sigel, R. Griesser, Chem. Soc. Rev. 2005, 34, 875.

[26] R. K. O. Sigel, H. Sigel, Met. Ions Life Sci. 2007, 2,109 .

[27] R. K. O. Sigel, B. Song, H. Sigel, J. Am. Chem. Soc. 1997, 119, 744.

[28] B. Knobloch, B. Nawrot, A. Okruszek, R. K. O. Sigel, Chem. Eur. J. 2008, 14, 3100.

[29] B. Knobloch, D. Suliga, A. Okruszek, R. K. O. Sigel, Chem. Eur. J. 2005, 11, 4163.

[30] B. Knobloch, H. Sigel, A. Okruszek, R. K. O. Sigel, Org. Biomol. Chem. 2006, 4, 1085.

[31] B. Knobloch, H. Sigel, A. Okruszek, R. K. O. Sigel, Chem. Eur. J. 2007, 13, 1804.

[32] B. Knobloch, R. K. O. Sigel, B. Lippert, H. Sigel, Angew. Chem. Int. Ed. 2004, 43, 3793.

[33] R. K. O. Sigel, H. Sigel, Acc. Chem. Res. 2010, in press.

[34] J. Schnabl, R. K. O. Sigel, www.minas.uzh.ch, 2007

[35] R. Zhao, D. Rueda, Methods 2009, 49, 112

[36] J. A. Cruz, E. Westhof, Cell 2009, 136, 604

[37] R. Das, L. W. Kwok, I. S. Millett, Y. Bai, T. T. Mills, J. Jacob, G. S. Maskel, S. Seifert, S. G. J. Mochrie, P. Thiyagarajan, S. Doniach, L. Pollack, D. Herschlag, J. Mol. Biol. 2003, 332, 311.

[38] S. A. Woodson, Curr. Op. Chem. Biol. 2005, 9 ,

[39] C. Waldsich, A. M. Pyle, Nature Struct. Mol. Biol. 2007, 14, 37

[40] A. M. Pyle, O. Fedorova, C. Waldsich, Trends Biochem. Sci. 2007, 32, 138

[41] O. Fedorova, N. Zingler, Biol. Chem. 2007, 388, 665.

[42] M. Steiner, K. S. Karunatilaka, R. K. O. Sigel, D. Rueda, Proc. Natl. Acad. Sci. USA 2008, 105, 13853.

[43] M. Steiner, D. Rueda, R. K. O. Sigel, Angew. Chem. Int. Ed. 2009, 48, 9739.

[44] S. Johannsen, S. Paulus, N. Düpre, J. Müller, R. K. O. Sigel, J. Inorg. Biochem. 2008, 1141

[45] Y. Tanaka, S. Oda, H. Yamaguchi, Y. Kondo, C. Kojima, A. Ono, J. Am. Chem. Soc. 2007, 129 , 244.

[46] S. Johannsen, N. Megger, D. Böhme, R. K. O. Sigel, J. Müller, Nature Chem. 2010, 2, 229.

[47] K. Tanaka, G. H. Clever, Y. Takezawa, Y Yamada, C. Kaul, M. Shionoya, T. Carell, Nature Nanotech. 2006, $1,190$.

[48] J. Müller, Eur. J. Inorg. Chem. 2008, 3749.

[49] A. Roth, R. R. Breaker, Annu. Rev. Biochem. 2009, 78, 305 .

[50] S. Gallo, S. Mundwiler, R. Alberto, R. K. O. Sigel, 2010, in revision.

[51] S. Gallo, M. Oberhuber, R. K. O. Sigel, B. Kräutler, ChemBioChem 2008, 9, 1408.

[52] A. S. Mironov, I. Gusarov, R. Rafikov, L.
E. Lopez, K. Shatalin, R. A. Kreneva, D. A. Perumov, E. Nudler, Cell 2002, 111, 747 .

[53] A. Nahvi, N. Sudarsan, M. S. Ebert, X. Zou, K. L. Brown, R. R. Breaker, Chem. Biol. 2002, 9 , 1043.

[54] A. G. Vitreschak, D. A. Rodionov, A. A. Mironov, M. S. Gelfand, Trends Genetics 2004, $20,44$.

[55] N. Sudarsan, J. E. Barrick, R. R. Breaker, RNA 2003, 9, 644 .

[56] S. Thore, M. Leibundgut, N. N. Ban, Science 2006, $312,1208$.

[57] T. Kubodera, M. Watanabe, K. Yoshiuchi, N. Yamashita, A. Nishimura, S. Nakai, K. Gomi, H. Hanamoto, FEBS Lett. 2003, 555, 516.

[58] M. T. Cheah, A. Wachter, N. Sudarsan, R. R. Breaker, Nature 2007, 447, 497.

[59] M. Mandal, B. Boese, J. E. Barrick, W. C Winkler, R. R. Breaker, Cell 2003, 113, 577.

[60] K. F. Blount, R. R. Breaker, Nature Biotechnol. 2006, 24, 1558.

[61] R. T. Batey, S. D. Gilbert, R. K. Montange, Nature 2004, 432, 411.

[62] A. Serganov, Y. R. Yuan, O. Pikovskaya, A. Polonskaia, L. Malinina, A. T. Phan, C. Hobartner, R. Micura, R. R. Breaker, D. J. Patel, Chem. Biol. 2004, 11, 1729.

[63] C. Lu, A. M. Smith, R. T. Fuchs, F. Ding, K Rajashankar, T. M. Henkin, A. Ke, Nature Struct. Mol. Biol. 2008, 15, 1076.

[64] W. C. Winkler, A. Nahvi, J. A. Collins, R. R. Breaker, Nature 2004, 428, 281.

[65] M. Mandal, R. R. Breaker, Nature Struct. Mol. Biol. 2004, 11, 29.

[66] M. Mandal, M. Lee, J. E. Barrick, Z. Weinberg, G. M. Emilsson, W. L. Ruzzo, R. R. Breaker, Science 2004, 306, 275.

[67] N. Sudarsan, M. C. Hammond, K. F. Block, R. Welz, J. E. Barrick, A. Roth, R. R. Breaker, Science 2006, 314, 300

[68] A. Gutierrez-Preciado, R. A. Jensen, C. Yanofsky, E. Merino, Trends Genet. 2005, 21, 432.

[69] W. C. Winkler, R. R. Breaker, Апnи. Rev Microbiol. 2005, 59, 487.

[70] M. D. Lundrigan, W. Koster, R. J. Kadner, Proc Natl. Acad. Sci. USA 1991, 88, 1479.

[71] A. Nahvi, J. E. Barrick, R. R. Breaker, Nucleic Acids Res. 2004, 32, 143.

[72] X. W. Nou, R. J. Kadner, Proc. Natl. Acad. Sci. USA 2000, 97, 7190

[73] C. V. Franklund, R. J. Kadner, J. Bacteriol. 1997, 179, 4039.

[74] S. Ravnum, D. I. Andersson, Mol. Microbiol 1997, 23, 35

[75] A. G. Vitreschak, D. A. Rodionov, A. A. Mironov, M. S. Gelfand, RNA 2003, 9, 1084.

[76] R. M. Jeter, B. M. Olivera, J. R. Roth, J. Bacteriol. 1984, 159, 206.

[77] P. Chen, M. Ailion, N. Weyand, J. Roth, J. Bacteriol. 1995, 177, 1461.

[78] K. Heller, R. J. Kadner, J. Bacteriol. 1985, 161 , 904

[79] C. Bradbeer, J. Bacteriol. 1993, 175, 3146.

[80] D. P. Chimento, A. K. Mohanty, R. J. Kadner, M C. Wiener, Nature Struct. Biol. 2003, 10, 394.

[81] M. Ailion, J. R. Roth, J. Bacteriol. 1997, 179, 6084.

[82] N. H. Georgopapadakou, A. I. Scott, J. Theor Biol. 1977, 69, 381

[83] A. Eschenmoser, Angew. Chem., Int. Ed. 1988, $27,5$.

[84] 'Vitamin $B_{12}$ and $B_{12}$-Proteins', Eds. B. Kräutler, D. Arigoni, B. T. Golding, Wiley- $\mathrm{VCH}$, Weinheim, 1998

[85] W. Gilbert, Nature 1986, 319, 618.

[86] J. R. Lorsch, J. W. Szostak, Biochemistry 1994, 33, 973.

[87] D. Sussman, J. C. Nix, C. Wilson, Nature Struct. Biol. 2000, 7, 53 . 